\title{
Analysis of the Mechanical Response of Asphalt Pavement Under Water-Stress Coupling
}

\author{
Kun $\mathrm{WANG}^{\mathrm{a}}$, Mingjun $\mathrm{WU}^{\mathrm{a}}$, Peng $\mathrm{HU}^{\mathrm{a}, 1}$ and Baoqun $\mathrm{WANG}^{\mathrm{a}}$ \\ ${ }^{a}$ Department of Civil Engineering, Shandong Jiaotong University, Ji'nan 250031, \\ China
}

\begin{abstract}
In order to study the mechanism of water damage of an asphalt pavement, the FLAC3D program was adopted to model and analyze the mechanical response of a saturated asphalt pavement under instantaneous vehicle load. The results show that the horizontal stress, vertical stress and shear stress of an asphalt concrete pavement increase with the increase of instantaneous load. The surfaces of asphalt pavement structural layers are most vulnerable to damage. The horizontal stress, vertical stress and shear stress decrease sharply with the instantaneous dynamic load decreasing to zero. The horizontal stress reaches maximum value at the interface between the base and the large stone porous mixture (LSPM) layer, while the maximum vertical and shear stresses occur on the surface layer of the saturated asphalt pavement. The deformation decreases almost linearly from the surface of the asphalt pavement to the subgrade, and the pore water pressure was little influenced by the transient load.
\end{abstract}

Keywords. FLAC3D, saturated asphalt pavement, instantaneous vehicle load, mechanical response, water-stress coupling

\section{Introduction}

Due to the direct exposure of asphalt pavement to the environment, various distress are caused by the external climate [1-4]. Significantly, asphalt pavement is subjected to washing and soaking by rain water. The asphalt pavement in Shandong province is affected by heavy loads and heavy precipitation. Studies have shown that water-stress coupling is one of the causes of early destress in asphalt pavement, including cracking and moisture damage [5-7].

Many studies have been carried out into the causes and prevention measures of asphalt pavement distress. Yang suggested to add the gradation and porosity as the technical indicators of the asphalt mixture because the water in the pavement will cause asphalt to peel off [8]. Lei Liu established a hydraulic-mechanical coupling model to simulate the extent of the damage of the asphalt pavement, the results show that water has a significance role to improve the pavement performance and durability [9]. Sun also established a three-dimensional finite element model to simulate the dynamic responses of the pavement with saturated water, the result are

${ }^{1}$ Peng Hu, Department of Civil Engineering, Shandong Jiaotong University, China; E-mail: 204021@sdjtu.edu.cn. 
almost same [10]. Abo-Qudais [11], WentaoWang [12] demonstrated that air void distribution and connectivity lead to moisture damage in asphalt mixtures. Studies into the mechanical response of asphalt pavement under water-stress coupling are incomplete, and most of them use the symmetrical finite element simulation method [13].

Based on the pavement structure of a new expressway in Shandong Province, the FLAC3D program is used to simulate changes in strain, stress and pore water pressure in a saturated asphalt pavement under different instantaneous loads. The research results will helps to explore the early damage mechanisms of asphalt pavement and provides a theoretical basis for effectively controlling early asphalt pavement distress.

\section{Modeling}

\subsection{Model Boundary}

A two-dimensional model was used for the simulation. The pavement structure: $4 \mathrm{~cm}$ SMA(upper surface), $6 \mathrm{~cm}$ AC-20(middle surface), $8 \mathrm{~cm}$ AC 25 (bottom surface), $36 \mathrm{~cm}$ cement treated crushed stone(base), lime-flyash soil(subbase), subgrade.

The model size is taken as $4 \mathrm{~m}^{*} 2 \mathrm{~m}$, that is to say, the lateral dimension is $4 \mathrm{~m}$ and the vertical depth is $2 \mathrm{~m}$. The seepage boundary is as follows: the upper, left and right boundary of the model are the water-permeable boundary; the bottom boundary restricts the vertical deformation and it is set as the impervious boundary. At the same time, to eliminate the influence of the boundary reflection wave on the dynamic analysis, the perimeter boundary of the model is set as the static boundary condition.

\subsection{Model Load}

The parameters of this numerical simulation analysis are taken according to the Specifications of Asphalt Pavement Design in China (JTG D50-2017). The standard axle load is $100 \mathrm{KN}$, the tire pressure applied to pavement is $0.7 \mathrm{MPa}$. Recent studies have found that the force acting at a certain point on the asphalt surface layer is equivalent to the half sinusoidal load distribution, so the same path was taken in this paper. The action time of vehicle load on the asphalt concrete pavement surface is assumed to be $T$, and the entire analysis time period is assumed to be Ta. The relationship between vehicle load and time is as shown in equations (1) and (2):

$$
\begin{aligned}
& \begin{cases}q=q_{\max } \sin \left|\frac{\pi t}{T}\right| & 0 \leq t \leq T \\
q=0 & T \leq t \leq T_{a}\end{cases} \\
& T=\frac{12 d}{V}
\end{aligned}
$$

Where $\mathrm{Ta}$ is load time, $\mathrm{d}$ is equivalent circle radius of single wheel pressure transmitting surface, and V is vehicle speed. 
Assuming the vehicle running speed $\mathrm{V}$ is $100 \mathrm{~km} / \mathrm{h}$, the time $\mathrm{T}$ of the vehicle load acting on it in the semi-sinusoidal period is $0.046 \mathrm{~s}$, and the time step of an analytical cycle is $0.2 \mathrm{~s}$. The functional relationship of vehicle load changing with time in a period is shown in figure 1.

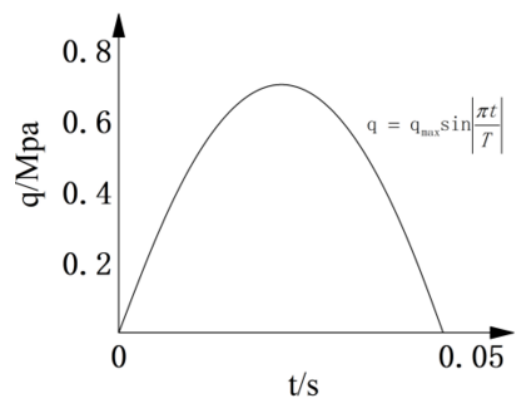

Figure 1. Load function curve.

\subsection{Material Parameters}

According to the relevant references and laboratory tests, the physical and mechanical material parameters for each layer of the asphalt pavement are shown in table 1.

Table 1. Material parameters

\begin{tabular}{llllll}
\hline Material & Depth/cm & Modulus $/ \mathrm{MPa}$ & $\begin{array}{l}\text { Poisson's } \\
\text { ratio }\end{array}$ & $\begin{array}{l}\text { (Permeability coefficient) } \\
/ \mathrm{cm} \cdot \mathrm{s}^{-1}\end{array}$ & $\begin{array}{l}\text { Dampin } \\
\mathrm{g} \text { ratio }\end{array}$ \\
\hline SMA & 4 & 1300 & 0.3 & $1.00 \mathrm{E}-05$ & 0.05 \\
AC-20 & 6 & 1200 & 0.35 & $1.00 \mathrm{E}-05$ & 0.05 \\
AC-25 & 8 & 1400 & 0.35 & $1.00 \mathrm{E}-05$ & 0.05 \\
cement treated & 36 & 1500 & 0.25 & $1.00 \mathrm{E}-04$ & 0.05 \\
$\begin{array}{l}\text { crushed stone } \\
\text { lime-flyash soil }\end{array}$ & 20 & 700 & 0.3 & $1.00 \mathrm{E}-05$ & 0.05 \\
subgrade & 114 & 40 & 0.4 & $1.00 \mathrm{E}-05$ & 0.05 \\
\hline
\end{tabular}

The permeability coefficient $\mathrm{K}_{\mathrm{f}}$ in FLAC3D is different from the $\mathrm{K}$ in conventional geotechnical calculations, so conversion is needed. The mutual conversion formula is as follows and The conversion parameters for FLAC3D are shown in table 2.

$$
K_{f}=K /\left(g \rho_{w}\right)
$$

Table 2. Material parameters for FLAC3D

\begin{tabular}{llllll}
\hline Material & $\begin{array}{l}\text { Depth/ } \\
\mathrm{cm}\end{array}$ & $\begin{array}{l}\text { Modulus } \\
\text { /MPa }\end{array}$ & $\begin{array}{l}\text { Poisson' } \\
\text { s ratio }\end{array}$ & $\begin{array}{l}\text { Permeability coefficient } \\
/ \mathrm{cm} \cdot \mathrm{S}^{-1}\end{array}$ & $\begin{array}{l}\text { Damping } \\
\text { ratio }\end{array}$ \\
\hline SMA & 4 & 1300 & 0.3 & $1.02 \mathrm{E}-11$ & 0.05 \\
AC-20 & 6 & 1200 & 0.35 & $1.02 \mathrm{E}-11$ & 0.05 \\
$\begin{array}{l}\text { AC-25 } \\
\text { cement treated }\end{array}$ & 8 & 1400 & 0.35 & $1.02 \mathrm{E}-11$ & 0.05 \\
$\begin{array}{l}\text { crushed stone } \\
\text { lime-flyash soil }\end{array}$ & 36 & 1500 & 0.25 & $1.02 \mathrm{E}-10$ & 0.05 \\
subgrade & 20 & 700 & 0.3 & $1.02 \mathrm{E}-11$ & 0.05 \\
\hline
\end{tabular}


A simple variable method was employed to analyze the dynamic response characteristics of the saturated asphalt pavement under vehicle load. Three monitoring points were set in the model to observe the variation of stress, strain and pore water pressure. The specific positional arrangement of the observation points and the different positional relationship of the vehicle load are shown in figure 2.

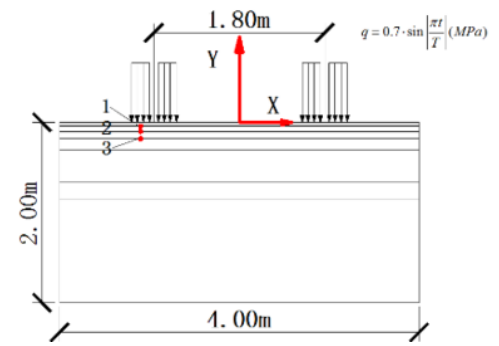

Figure 2. Observation point arrangement and load distribution.

In this numerical simulation model, an observation point is positioned directly below the center of one of the leftmost wheels, and its position in the $\mathrm{x}$ direction is -1.1 m. Additionally, observation points are respectively located at the interface of different asphalt pavement layers.

\section{Results and Discussion}

\subsection{Stress Response Analysis}

In the case where the thickness of the asphalt surface layer is equal to $18 \mathrm{~cm}$, four different time, $\mathrm{t}=0.023 \mathrm{~s}, \mathrm{t}=0.046 \mathrm{~s}, \mathrm{t}=0.1 \mathrm{~s}, \mathrm{t}=0.2 \mathrm{~s}$, are selected in the model to analyze the changes of stress, strain and pore water pressure. Stress is divided into three types: horizontal stress, vertical stress and shear stress. The results are shown in figure 3.

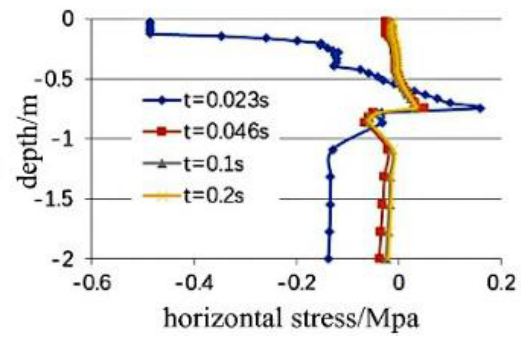

(a) The horizontal stress below the vehicle load along the depth. 


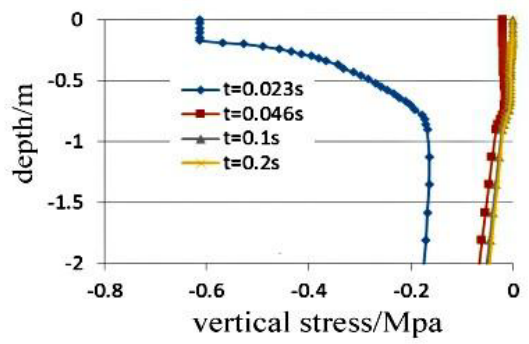

(b) The vertical stress below the vehicle load along the depth.

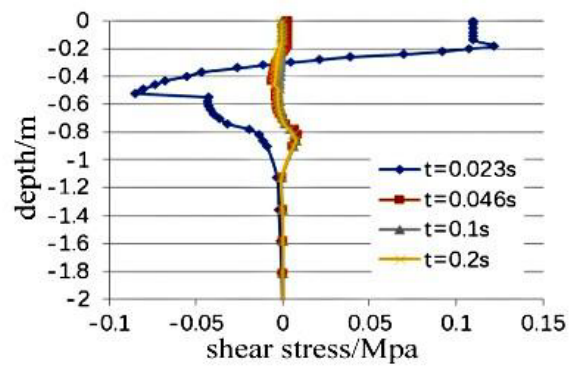

(c) The shear stress below the vehicle load along the depth.

Figure 3. The stress changes in the saturated asphalt pavement.

It can be seen from figure 3(a) that for the stress change in the horizontal direction, when $\mathrm{t}$ is $0.023 \mathrm{~S}$, the horizontal compressive stress reaches the maximum, which is $0.48 \mathrm{Mpa}$. The maximum tensile stress in the horizontal direction is $0.2 \mathrm{Mpa}$ at the interface between the base and the subbase, while in the subbase and the subgrade, the structural stress expressed as compressive stress and steadily maintains at about $0.14 \mathrm{Mpa}$.

Figure 3(b) shows that the maximum compressive stress is generated at the surface of the asphalt pavement. When $\mathrm{t}$ is $0.023 \mathrm{~S}$, the instantaneous dynamic load reaches the maximum, at the same time the vertical stress reaches the maximum at the surface. The vertical stress increases with the vertical depth. From this, it can be judged that the vertical stress is most affected by the instantaneous vertical load.

By figure 3(c), the shear stress reaches a maximum value at the time when the instantaneous dynamic load reaches the maximum at $\mathrm{t}=0.023 \mathrm{~s}$ and the maximum shear force appears at the surface layer of SMA, AC-20, AC-25, and the base. So, it is necessary to strengthen the shearing resistance of the asphalt pavement surface.

\subsection{Strain Response Analysis}

The deformations of $\mathrm{t}=0.023 \mathrm{~s}, \mathrm{t}=0.046 \mathrm{~s}, \mathrm{t}=0.1 \mathrm{~s}$, and $\mathrm{t}=0.2 \mathrm{~s}$ are analyzed according to the load-time history curve. The results indicate that the vertical deformation is the largest when the instantaneous dynamic load is the largest $(\mathrm{t}=0.023 \mathrm{~s})$, and the deformation presents a linear reduction from the asphalt pavement surface to the subgrade. When $t$ is $0.046 \mathrm{~s}$, the instantaneous dynamic load becomes 0 and the asphalt pavement structure rebounds, but there is still residual deformation. When $\mathrm{t}=0.1 \mathrm{~s}$, the residual deformation decreases, which is close to 0 , as shown in figure 4 . 


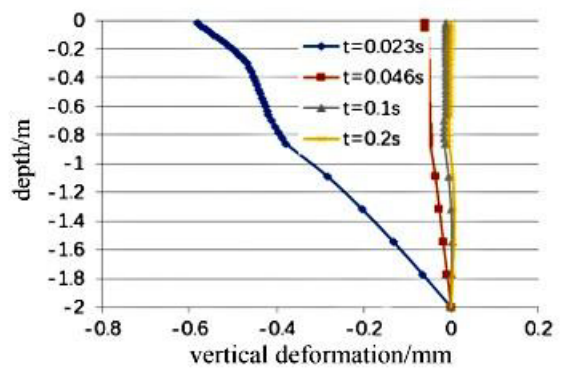

Figure 4. The vertical deformation below the load along the depth.

\subsection{Pore Water Pressure Response Analysis}

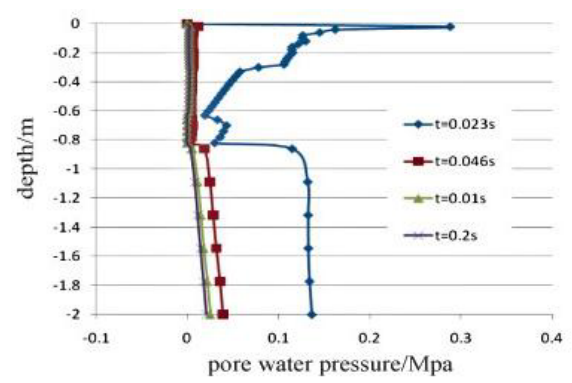

Figure 5. The pore water pressure below the load along the depth.

Figure 5 shows that when $\mathrm{t}=0.023 \mathrm{~s}$, the instantaneous dynamic load appears to peak at a value of $0.29 \mathrm{MPa}$, pore water pressure occurs on the surface of the asphalt pavement and the peak of pore water pressure appears on the pavement surface layer. At the same time, the pore water pressure accumulation zones occur on the asphalt pavement surface. When the instantaneous load is $0(\mathrm{t}=0.046 \mathrm{~s})$, the pore water pressure dissipates fast. When the mechanical boundary conditions return to the original state, the pore water stress disappears immediately. At this time, the maximum pore water pressure appears at the bottom of the numerical model. Thus, the instantaneous load has no effect on the pore water pressure in the saturated asphalt pavement layers.

\section{Conclusion}

In this paper, a model of a saturated asphalt pavement using the FLAC3D program was established to explore the mechanical response of an asphalt pavement under a waterstress coupling action, and the following conclusions are obtained:

1) The horizontal stress, vertical stress and shear stress of the pavement increase with the increase of instantaneous load, and the horizontal stress reaches a maximum value at the interface. In addition, the maximum vertical and shear stresses are distributed in the surface of the saturated asphalt pavement. Deformation decreases from the surface of the asphalt pavement to the subgrade, and the pore water pressure is little influenced by the transient load.

2) The maximum compressive stress is generated on the surface, and that the tensile 
stress appeared at the interface between the subbase and the subgrade. The deformation rebounds after the transient load is reduced, but some residual structural deformation remains.

3) The maximum pore water pressure appears on the surface layer of the asphalt pavement. With the depth increases, the pore water pressure quickly approaches zero.

\section{Acknowledgments}

This work was supported by the National Key R\&D Program of China (2018YFB1600100).

\section{References}

[1] Sun YZh, Guo R, Wang XCh, Ning XH. Dynamic response characteristics of permeable asphalt pavement based on unsaturated seepage. International Journal of Transportation Science and Technology.2019 Dec; 8(4): 403-417.

[2] Artur O, Larysa S, Andrii B, Natalia S. Evaluation of the durability of asphalt concrete on polymer modified bitumen. Proceedings of E3S Web of Conferences. 2020 May; 164: 10.

[3] Liu XL, Zhang XM. Asphalt pavement dynamic response under different vehicular speeds and pavement roughness. Road Materials and Pavement Design. 2021 May; 22(6): 1287-1308.

[4] Zhang K, Luo YF, Chen F, Han FF. Performance evaluation of new warm mix asphalt and water stability of its mixture based on laboratory tests. Construction and Building Materials. 2020 Apr;241.

[5] Yuan JW, Hu M, Liu ZhH, Li TT, Chen ShB, Gao J. Experimental study on interlayer mechanical properties of semi-rigid base asphalt pavement Using interlayer treatment method. IOP Conference Series: Earth and Environmental Science. 2021 April;719(3).

[6] Wang WT, Wang LB, Xiong HCh, Luo R. A review and perspective for research on moisture damage in asphalt pavement induced by dynamic pore water pressure. Construction and Building Materials. 2019 April; 204: 631-642.

[7] Liu KF, Deng LF, Zheng JY. Nanoscale study on water damage for different warm mix asphalt binders. International Journal of Pavement Research and Technology. 2017; 10(3): 405-413.

[8] Yang Q G, Ning J Ch. The environmental influence of asphalt pavement and countermeasures. Energy Procedia. 2011 June;5:2432-2436.

[9] Xue Q, Liu L. Hydraulic-stress coupling effects on dynamic behavior of asphalt pavement structure material. Construction and Building Materials. 2013 June;43:31-36

[10] Nejad FM, Asadi M, Hamedi GH. Determination of moisture damage mechanism in asphalt mixtures using thermodynamic and mix design parameters. International Journal of Pavement Research and Technology. 2020 March; 13: 176-186.

[11] Wang WT, Wang LB, Xiong HCh, Luo R. A review and perspective for research on moisture damage in asphalt pavement induced by dynamic pore water pressure. Construction and Building Materials. 2019 April; 204: 631-642.

[12] Sun YZh, Guo R, Gao L, Wang JCh, Wang XCh, Yuan XZh. Study on dynamic response characteristics of saturated asphalt pavement under multi-field coupling. Materials. 2019 March; 12(6): 959.

[13] Tian R Y, Huang X M, Yin D Q, etc. Stress characteristics of CRCP pavement in permafrost region based on coupled interaction of moisture-heat-stress fields. Journal of Southeast University (Natural Science Edition). 2020 March; 50(2): 286-293. 